\title{
DETERMINANTES DE LA DESERCIÓN ESCOLAR Y EL TRABAJO ADOLESCENTE EN BOLIVIA
}

Joaquín Morales y Yelussa Vargas

\section{RESUMEN}

La investigación explora los determinantes detrás de la decisión de estudiar o de trabajar de los adolescentes bolivianos. Encontramos que, aunque el trabajo adolescente está asociado al abandono escolar, estas categorías no son mutualmente exclusivas; en efecto, existen adolescentes que trabajan y estudian simultáneamente, y adolescentes que no realizan ninguna de las dos actividades. Usando un modelo biprobit, encontramos que la decisión de estudiar o trabajar está fuertemente influenciada por el ingreso, pero también por la educación de los padres, por diferencias en la estructura familiar y por diferencias regionales.

Palabras Clave: Trabajo Adolescente, Deserción Escolar, Modelos Probit Bivariados.

DOI: $10.23881 /$ idupbo.018.2-6e 